\title{
Factors Influencing Satisfaction with Service Delivery Among National Health Insurance Scheme Enrollees in Ibadan, Southwest Nigeria
}

Journal of Patient Experience

Volume 9: 1-9

(C) The Author(s) 2022

Article reuse guidelines:

sagepub.com/journals-permissions DOI: 10.1 I 77/2374373522।074|86 journals.sagepub.com/home/jpx

@SAGE

\author{
David Ayobami Adewole, MBChB, MSc, PhD, FMCPH' (D), \\ Steve Reid, MBChB, PhD ${ }^{2}$, Tolu Oni, MBBS, MD (Res) ${ }^{3}$, \\ and Ayo Stephen Adebowale, $\mathrm{PhD}^{4}$
}

\begin{abstract}
Perceived quality of care is a determinant of uptake of health services. This study aimed to assess the determinants of quality of care of enrollees in the National Health Insurance Scheme (NHIS) in Nigeria. The outcome was satisfaction with health care services, which was used as a proxy for quality. Findings will assist in the intervention to enhance enrollment in the scheme and for universal health coverage attainment. This was a descriptive cross-sectional study conducted among enrollees in selected NHIS facilities in Ibadan, Nigeria. Data on satisfaction with health care were collected among selected 432 enrollees with the aid of an adapted semi-structured WHO-USAID interviewer-administered questionnaire. Data were analyzed using chi-square and multiple logistic regression models $(\alpha=0.05)$. Among predictors of satisfaction with health services were younger age $(O R=1.85,95 \% \mathrm{Cl}=1.05-3.25, p=.024)$, working in the private sector $(O R=1.84$, $95 \% \mathrm{Cl}=1.03-3.28, p=.022)$, and seeking information about quality of services prior enrollment $(O R=1.63,95 \%$ $\mathrm{Cl}=1.04-2.53, p=.013)$. Targeted intervention based on the findings of this study should be implemented to improve satisfaction with the services offered.
\end{abstract}

\section{Keywords}

satisfaction, National Health Insurance Scheme, quality of health care, enrollees, health facilities, private sector, health care providers.

\section{Introduction}

Patient satisfaction with services is a proxy of the quality of health care, and it measures the level of contentment with services received in a health system (1). Studies have shown that satisfaction is correlated with utilization and follow-up with health care interventions and compliance with prescribed treatment regimens (2). Satisfaction with care could also enhance the tendency of care recipients to serve as agents of information dissemination and promote health intervention among potential beneficiaries (3). Thus, satisfaction could predict to some extent the sustainability of a health care program after implementation.

There have been divergent views about the association between some sociodemographic factors and satisfaction. While some studies asserted that certain sociodemographic characteristics such as age, sex, marital status, and occupational status are not associated with satisfaction (4), the majority believed that they influence it (5). Type of occupation among other attributes is also inclusive (6). Satisfaction with care

\footnotetext{
1 Department of Health Policy and Management, Faculty of Public Health, College of Medicine, University of Ibadan, Ibadan, Nigeria

${ }^{2}$ Primary Health Care Directorate, Faculty of Health Sciences, University of Cape Town, Observatory, South Africa

${ }^{3}$ Medical Research Council Epidemiology Unit, University of Cambridge, Cambridge, UK

${ }^{4}$ Department of Epidemiology and Medical Statistics, Faculty of Public Health, University of Ibadan, Ibadan, Nigeria
}

Corresponding Author:

David Ayobami Adewole, Department of Health Policy and Management, Faculty of Public Health, College of Medicine, University of Ibadan, Ibadan, Nigeria.

Email: ayodadewole@yahoo.com 
has also been linked with the level of education and economic status (7). In some separate studies conducted in developing and developed countries, findings have also attributed satisfaction with the type of health care facility where the care was received-public or private (8). Victoor and colleagues (9), as well as Geberu and team (10) in separate studies, affirmed that health literacy about the quality of care available, existence of multiple morbidities, and seeking information about the quality of care influence satisfaction. Opposing findings have been reported in other studies; while some reported a high level of satisfaction, some reported a low level (of satisfaction) with care $(10,11)$.

In collaboration with accredited health insurers (the Health Maintenance Organizations-HMOs) and healthcare providers, in both the public and the private sectors, the National Health Insurance Scheme (NHIS) operates a social health insurance scheme in Nigeria. The main goal of the scheme is to minimize inequity of access to healthcare services and improve population health indices in the country. Statutorily, policy direction about the scheme is provided by the NHIS. The NHIS is also responsible for the accreditation of eligible HMOs and healthcare providers. There are three levels (e.g., the primary, secondary, and tertiary) of healthcare in Nigeria. Of these three levels, the secondary and the tertiary levels are eligible to provide care to enrollees under the scheme. Although the secondary and the tertiary levels of healthcare serve as primary care providers, however, in addition, the tertiary level serves as a referral point for the secondary care level when necessary (12).

Current population coverage under the NHIS is less than $3 \%$ of the total population $(12,13)$. The present population coverage and the rate of progress are unlike the experience in comparable schemes in related settings in Africa and Latin American countries $(14,15)$. Poor satisfaction with care has been cited as a factor of low uptake of health interventions (3). This study aimed to assess the determinants of quality of care of enrollees in the NHIS in Nigeria. The outcome was satisfaction with health care services, which was used as a proxy for quality. Findings would be useful for strategic policies to improve enrollment in the NHIS and the achievement of universal health coverage.

\section{Methodology}

\section{Materials and Methods}

\section{Study Design and Area}

This is a descriptive cross-sectional study. It was conducted in the 11 local government areas (LGAs) of Ibadan, Nigeria. The estimated population of the 11 LGAs was about 3 million based on the projection using the figure from the 2006 Nigeria population census as the base year (16). There were several health care facilities at the primary, secondary, and tertiary care levels in the study area.

\section{Sample Size Estimation}

In this study, satisfaction with care provided in health care facilities is the main outcome variable. The proportion of enrollees who were satisfied with the choice of provider in a previous study in Nigeria was $40.7 \%$ (1). Using the Leslie-Kish formula, (17) calculated the minimum sample size was 420 .

\section{Sampling Strategy}

A list of all health care facilities within the study area (11 LGAs); was obtained from the Oyo State Ministry of Health. Next, a list of all NHIS accredited facilities was obtained from the NHIS Office in Ibadan. As, for the choice of enrollees, 11 (11) NHIS accredited health facilities, 1 (1) facility in each of the 11 LGAs was selected by simple random sampling. The selected facilities were visited and the number of enrollees in each of the selected health facilities was verified. Proportionate allocation of the estimated sample size (420) was done based on the number of enrollees across the selected NHIS accredited facilities. All selected 11 (11) healthcare facilities were secondary level facilities (public, private non-faith-based, and private faith-based). There was only one tertiary health facility in the study area. Due to the small number (only one [1] in the study area) compared to NHIS accredited secondary healthcare facilities, and also because of better infrastructural facilities and human resources availability compared to secondary health care facilities, the only available tertiary health care facility in the study area was not selected. Data collection spanned 3 weeks.

\section{Participants' Selection}

A list of NHIS enrollees waiting to receive care in the outpatient section of a selected health facility was obtained from the medical records department of the facility. Eligible individuals were the principal enrollees or spouses (excluding dependents under the age of 18 years) and had enrolled in the facility for at least 1 year before the commencement of the study. This was to increase the possibility that study participants had an appreciable level of interaction with the health system under the scheme that will enable appropriate responses from them (1). Among this population, enrollees who began using the selected facilities before the commencement of the health insurance scheme were excluded from the study as well as enrollees who were health care workers in the selected facilities. The total number of eligible individuals present in the clinic was used to generate a sampling frame. A sampling interval was determined, and systematic random sampling was used to select eligible participants. Systematic sampling was chosen because it eliminates the phenomenon of clustered selection and has a low probability of data contamination. The disadvantage of using a systematic sampling technique is noted and is considered a study 
limitation. The hospital card numbers of the enrollees who were interviewed were documented and kept safe.

\section{Data Collection}

Selected enrollees in the selected NHIS accredited health facilities were interviewed with the aid of an adapted WHO-USAID Demographic and Health Survey semi-structured intervieweradministered questionnaire (18). Enrollees who had earlier been interviewed during the study but came back to the clinic for care were deliberately identified and excluded. This was done so as not to interview such individuals a second time, and it was carried out by cross-checking the hospital number of the prospective interviewee (enrollee) in the list of hospital numbers that were earlier documented for safekeeping. This exercise was repeated daily until the allocated number of enrollees in each of the facilities was interviewed.

\section{Variables of Interest}

Dependent variable: Satisfaction as an Outcome variable. Satisfaction was measured with 22 questions adapted from the WHO-USAID questionnaire (18). The questions were based on infrastructural facilities and services received at the health facilities. Samples of these questions are as follows: (1) The cleanliness of the facility; (2) Availability of medicines at this facility; (3) Privacy from others seeing you being examined; (4) Waiting time to see a provider; (5) Opportunity to discuss problems on your health with nurse/doctor; (6) Amount of explanation you received about the problem or treatment; and (7) To what extent did the clinic meet all your health needs today.

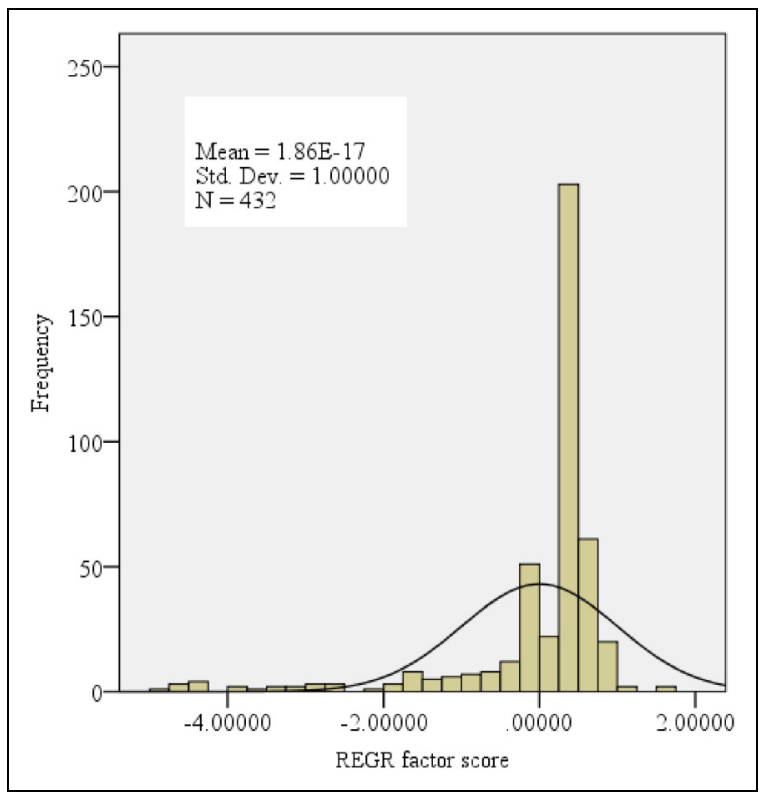

Figure I. The regression factor scores from principal component analysis (PCA) output.
Independent Variables. These include sociodemographic factors such as age, sex, marital status, socioeconomic status, occupation, seeking information on the quality of care, facility type, and knowledge of the scheme.

\section{Data Analysis}

Data were analyzed using STATA version 2.0 software and SPSS. A chi-square test was used to examine the association between sociodemographic characteristics and satisfaction with the health care facility. Following this, variables significant at the $10 \%$ level were entered into multiple logistic regression models to determine the strength of association between satisfaction and independent variables (predictors). The dependent variable, satisfaction, was classified into two categories, not satisfactory $=0$ or satisfactory $=1$.

Variables were selected from bivariate level to multivariate level using a $10 \%$ level of significance. However, the level of significance used to ascertain the relationship at the multivariate level was $5 \%$.

Table I. Sociodemographic Characteristics of Respondents.

\begin{tabular}{|c|c|c|}
\hline Variable & $\begin{array}{c}\text { Frequency } \\
n=432\end{array}$ & Percent \\
\hline \multicolumn{3}{|l|}{ Age group } \\
\hline$<35$ years & 101 & 23.4 \\
\hline 35 and above & 331 & 76.6 \\
\hline \multicolumn{3}{|l|}{ Sex } \\
\hline Male & 169 & 39.1 \\
\hline Female & 263 & 60.9 \\
\hline \multicolumn{3}{|l|}{ Marital status } \\
\hline Married & 415 & 96.1 \\
\hline Others & 17 & 3.9 \\
\hline \multicolumn{3}{|l|}{ Level of education } \\
\hline Less than tertiary & 88 & 20.4 \\
\hline Tertiary & 344 & 79.6 \\
\hline \multicolumn{3}{|l|}{ Occupation } \\
\hline Civil servant & 319 & 73.8 \\
\hline $\begin{array}{l}\text { Private (including organized private } \\
\text { sector) }\end{array}$ & 113 & 26.2 \\
\hline \multicolumn{3}{|l|}{ Socioeconomic status } \\
\hline Low & 177 & 41.0 \\
\hline High & 255 & 59.0 \\
\hline \multicolumn{3}{|l|}{ Presence of multiple morbidities } \\
\hline Absent & 298 & 68.9 \\
\hline Present & 134 & 31.1 \\
\hline \multicolumn{3}{|c|}{$\begin{array}{l}\text { Prior information about quality of care } \\
\text { in facility }\end{array}$} \\
\hline Yes & 291 & 67.4 \\
\hline No & $|4|$ & 32.6 \\
\hline \multicolumn{3}{|l|}{$\begin{array}{l}\text { Knowledge of NHIS facility closer to } \\
\text { residence }\end{array}$} \\
\hline Yes & 147 & 34.0 \\
\hline No & 285 & 66.0 \\
\hline \multicolumn{3}{|l|}{ Method of choice of facility } \\
\hline Personal choice & 320 & 74.1 \\
\hline Choice based on advice & 112 & 25.9 \\
\hline
\end{tabular}

Abbreviation: NHIS, National Health Insurance Scheme. 
Table 2. Percentage Distribution of Respondents According to Satisfaction by Sociodemographic Characteristics.

\begin{tabular}{|c|c|c|c|c|c|}
\hline \multirow[b]{2}{*}{ Background variables } & \multicolumn{2}{|c|}{ Satisfaction } & \multirow{3}{*}{$\begin{array}{c}\text { Total } \\
n=432\end{array}$} & \multirow[b]{3}{*}{$\chi^{2}$ value } & \multirow[b]{3}{*}{$p$-value } \\
\hline & Not satisfied & Satisfied & & & \\
\hline Total & I 48 (34.3) & $284(65.7)$ & & & \\
\hline Age & & & & 10.615 & .001 \\
\hline$<35$ years & $21(20.8)$ & $80(79.2)$ & 101 & & \\
\hline 35 and above & $127(38.4)$ & $204(61.6)$ & 331 & & \\
\hline Sex & & & & 0.052 & .819 \\
\hline Male & $59(34.9)$ & $110(65.1)$ & 169 & & \\
\hline Female & $89(33.8)$ & $174(66.2)$ & 263 & & \\
\hline Marital status & & & & 0.376 & .540 \\
\hline Married & |4| (34.0) & $274(66.0)$ & 415 & & \\
\hline Others & $7(4 \mid .2)$ & $10(58.8)$ & 17 & & \\
\hline Level of education & & & & 4.207 & 0.040 \\
\hline$<$ Tertiary & $22(25.0)$ & $66(75.0)$ & 88 & & \\
\hline Tertiary & $126(36.6)$ & $218(63.4)$ & 344 & & \\
\hline Base of occupation & & & & 14.863 & .000 \\
\hline Civil Service & $126(39.5)$ & $193(60.5)$ & 319 & & \\
\hline Private & $22(19.5)$ & $91(80.5)$ & 113 & & \\
\hline Economic status & & & & 0.001 & .978 \\
\hline Low & $67(34.2)$ & $129(65.8)$ & 196 & & \\
\hline High & $81(34.3)$ & $155(65.7)$ & 236 & & \\
\hline Multiple morbidities & & & & 0.406 & .524 \\
\hline Absent & $105(35.2)$ & $193(64.8)$ & 298 & & \\
\hline Present & $43(32.1)$ & 91 (67.9) & 134 & & \\
\hline Sought info & & & & 3.534 & .060 \\
\hline Yes & $91(31.3)$ & $200(68.7)$ & 291 & & \\
\hline No & $57(40.4)$ & $84(59.6)$ & $|4|$ & & \\
\hline Known of NHIS & & & & 7.314 & .007 \\
\hline Yes & 63 (42.9) & $84(57.1)$ & 147 & & \\
\hline No & $85(29.8)$ & $200(70.2)$ & 285 & & \\
\hline Facility type & & & & 11.317 & .003 \\
\hline Private & $99(4 I .1)$ & $142(58.9)$ & 241 & & \\
\hline Public & $19(26.8)$ & $52(73.2)$ & 71 & & \\
\hline Faith-based & $30(25.0)$ & $90(75.0)$ & 120 & & \\
\hline
\end{tabular}

Abbreviation: NHIS, National Health Insurance Scheme.

\section{Principal Component Analysis}

The method involved in this is as follows: Principal component analysis (PCA) was used to generate a satisfaction index. The generation was based on 22 questions. Each of the questions was assigned a weight generated through PCA. Thereafter, the satisfaction scores were standardized about a standard normal distribution $\left(\mu=0, \sigma^{2}=1\right)$. In the process, seven components were generated and the component with the highest percentage of total variance explained by initial eigenvalues (24.513\%), extraction sums of squared loadings $(24.513 \%)$, and rotation of sums of squared loading (20.165) were selected and disaggregated into two categories based on the median $(50$ percentiles $=$ 0.3323433 ) index since the distribution of the satisfaction index was skewed (Figure 1). Thus, scores of at least 0.3323433 were rated as satisfactory and unsatisfactory if otherwise.

\section{Results}

The total number of respondents eventually interviewed was $432(2.8 \%)$ above the minimum sample size. The majority were 35 years and above 331 (76.6\%), females 263 (60.9\%), and married 415 (96.1\%). Respondents with tertiary level of education were 344 (79.6\%), while those who were civil service employees were 319 (73.8\%) (Table 1). Less than a third, $117(27 \%)$ of the respondents scored a maximum attainable score of 22. Satisfaction with healthcare services were significantly higher among younger people, individuals with less than tertiary level of education and those from the private sector than among their counterparts $\left(\chi^{2}=10.615, \mathrm{p}=.001\right),\left(\chi^{2}=4.207, \mathrm{p}=.040\right)\left(\chi^{2}=14.863\right.$, $\mathrm{p}=.000)$, respectively. Similar findings were reported with those who claimed no knowledge of the scheme and those who patronized faith-based health facilities; $\left(\chi^{2}=7.314\right.$, $\mathrm{p}=.007),\left(\chi^{2}=11.317, \mathrm{p}=.003\right)$, respectively (Table 2$)$. 
Table 3. Logistic Regression Model of the Relationship Between Satisfaction and Background Characteristics.

\begin{tabular}{|c|c|c|c|c|c|}
\hline \multirow{2}{*}{$\begin{array}{l}\text { Background } \\
\text { variables }\end{array}$} & \multicolumn{2}{|c|}{ Unadjusted } & \multicolumn{2}{|c|}{ Adjusted } & \multirow[b]{2}{*}{$p$-value } \\
\hline & Odds ratio & $95 \% \mathrm{Cl}$ & Odds ratio & $95 \% \mathrm{Cl}$ & \\
\hline \multicolumn{6}{|l|}{ Age } \\
\hline$<35$ years & 2.37 & $1.39-4.03$ & 1.85 & $1.05-3.25$ & .024 \\
\hline 35 and above & 1.00 & & 1.00 & & \\
\hline \multicolumn{6}{|l|}{ Sex } \\
\hline Male & 1.00 & & & & \\
\hline Female & 1.05 & $0.69-1.58$ & & & \\
\hline \multicolumn{6}{|l|}{ Marital status } \\
\hline Married & 1.36 & $0.50-3.65$ & & & \\
\hline Others & 1.00 & & & & \\
\hline \multicolumn{6}{|c|}{ Level of education } \\
\hline$<$ Tertiary & 1.73 & $1.02-2.95$ & 1.64 & $0.92-2.90$ & .62 \\
\hline Tertiary & 1.00 & & 1.00 & & \\
\hline \multicolumn{6}{|l|}{ Occupation } \\
\hline Civil servant & 1.00 & & 1.00 & & \\
\hline Private & 2.70 & $1.6 I-4.53$ & 1.84 & $1.03-3.28$ & .022 \\
\hline \multicolumn{6}{|c|}{ Economic status } \\
\hline Low & 1.01 & $0.67-1.50$ & & & \\
\hline High & 1.00 & & & & \\
\hline \multicolumn{6}{|c|}{ Multiple morbidities } \\
\hline Absent & 1.00 & & & & \\
\hline Present & 1.15 & $0.74-1.78$ & & & \\
\hline \multicolumn{6}{|l|}{ Sought info } \\
\hline Yes & 1.49 & $0.98-2.27$ & 1.63 & $1.04-2.53$ & .013 \\
\hline No & 1.00 & & 1.00 & & \\
\hline \multicolumn{6}{|l|}{ Known of NHIS } \\
\hline Yes & 1.00 & & 1.00 & & \\
\hline No & 1.77 & $1.16-2.67$ & 1.65 & $1.06-2.55$ & .027 \\
\hline \multicolumn{6}{|l|}{ Facility type } \\
\hline Private & 1.00 & & 1.00 & & \\
\hline Public & 1.91 & $1.06-3.42$ & 1.399 & $0.72-2.69$ & .2 \\
\hline Faith-based & 2.09 & $1.28-3.40$ & 1.84 & $1.09-3.08$ & .03 \\
\hline
\end{tabular}

Abbreviation: NHIS, National Health Insurance Scheme.

Predictors of satisfaction with health services are younger age, working in the private sector, and seeking information about quality of services prior enrollment $(\mathrm{OR}=1.85,95 \% \mathrm{CI}$ $=1.05-3.25, \mathrm{p}=.024) ;(\mathrm{OR}=1.84,95 \% \mathrm{CI}=1.03-3.28, \mathrm{p}=$ $.022)$ and $(\mathrm{OR}=1.63,95 \% \mathrm{CI}=1.04-2.53, \mathrm{p}=0013)$ respectively. Likewise, having no knowledge about the scheme, and as well as receiving care in faith-based facilities predicts satisfaction with services than their respective counterparts; $(\mathrm{OR}=1.65$, $95 \% \mathrm{CI}=1.06-2.55, \mathrm{p}=.027)$ and $(\mathrm{OR}=1.84,95 \% \mathrm{CI}=1.09$ $3.08, \mathrm{p}=003$ ), respectively (Table 3 ).

Below is a graphical representation of the satisfaction score of respondents across public, non-faith-based, and faith-based private health care facilities. Overall satisfaction with the outpatient medical visit among respondents, which was a single-value score that summarized all the items under satisfaction with care assessment was the outcome variable for health care satisfaction in this study. There are two sections to the satisfaction assessment. One section has the questions as a dichotomous response; "Satisfied" and "Not satisfied". The other section has the questions as "Agreed", "Undecided", and "Disagree". "Undecided" and "Disagree" were collapsed into a single column as "Disagree". There were 11 (11) questions in each section. The questions assessed the structural and the process of care of the Donabedian Conceptual Framework. This included the assessment of the facility's physical infrastructure, the surrounding environment, the availability of medical equipment, drugs, and other consumables, and trained personnel. The process of care attempted to assess client-provider interaction and the process of care delivery. "Satisfied" and "Agree" have a score of 1 , while "Not satisfied" and "Disagree" each have a score of 0 . Thus, a maximum score of 22 was attainable across the two sections. Of a maximum score of 22 , overall, about $27 \%$ attained a total score achievable. However, $40 \%, 27 \%$, and $27 \%$ of those who patronized the public, private, and faith-based health care facilities attained a maximum satisfaction score of 22 (Figure 2).

\section{Discussion}

The degree of satisfaction with care has been described and defined as the gap between what is expected, and the 


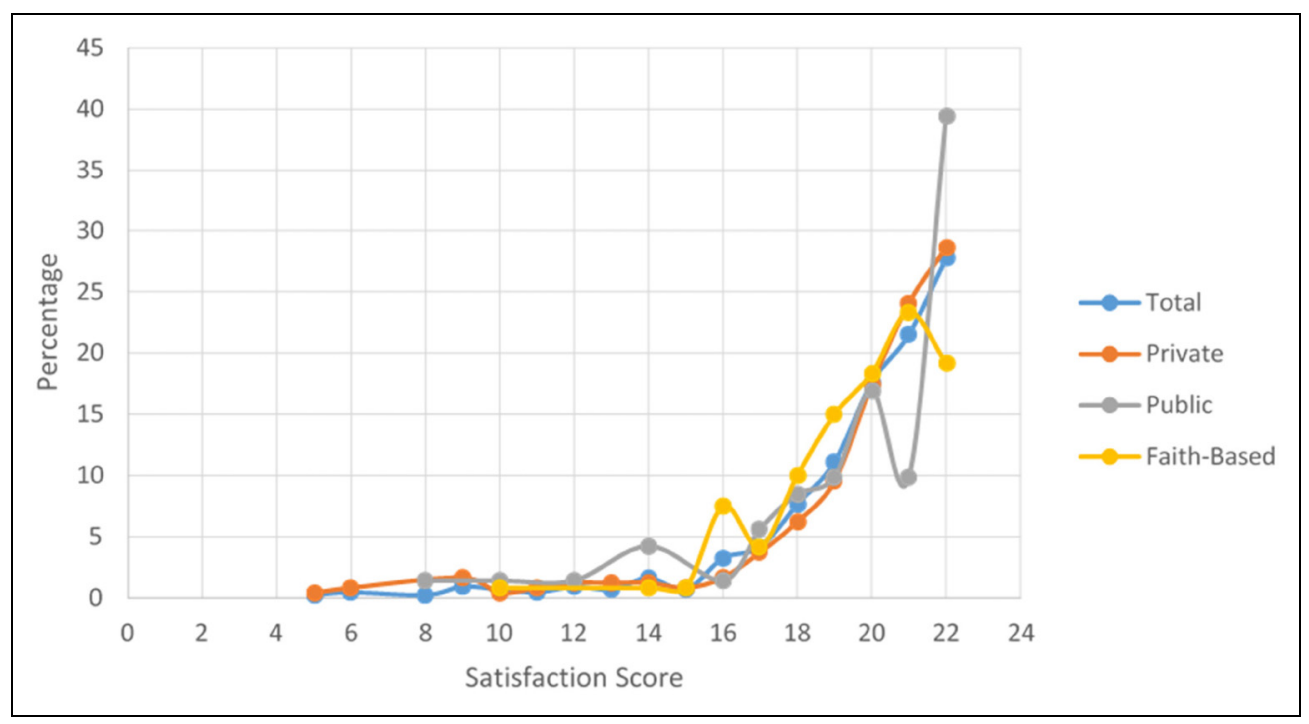

Figure 2. Satisfaction score by facility type.

reality of care obtained. Generally, there was a low level of satisfaction with care in this study. This is similar to a previous study conducted by Fufa and colleagues (11) among outpatient service consumers in a medical center in Southwest Ethiopia. However, it was in contrast to a higher level of satisfaction reported in yet another study carried out by Geberu and colleagues in some public hospitals in Addis Ababa, Ethiopia (10).

Evidence from previous studies has shown that sociodemographic variables of health care consumers and health system factors interact in diverse ways and predict satisfaction with health services received differently $(19,20)$.

In this study, younger age, employment in the private sector, seeking information about the quality of care were predictors of satisfaction with services. This is also the same with not knowing the NHIS and patronizing faith-based health facilities for care. In a study conducted among in-patient hospital clients in Ethiopia, Ambelie and colleagues (19) claimed that the younger, the more likely people were to be satisfied with health services. This was in agreement with a study by Footman and colleagues carried out in some countries in Eastern Europe in 2013 (21) and as well as in another study by Geberu and colleagues in Ethiopia (10). However, it was in disparity with a much later work conducted among patients in the outpatient departments of selected hospitals also in Ethiopia which reported satisfaction to be higher among older individuals (22). Satisfaction with care was also reported with older age in yet some other studies (20). Among these two different age groups, the phenomenon of exchange trust norm (23) that is, the tendency to be more satisfied with available care may have played out among younger people. This may have arisen since available health services may have easily met the less serious health needs among them unlike among older adults with likely multiple morbidities and the tendency to be less easily satisfied with basic care as a result of more health needs (19). This study suggests that younger individuals were more likely and easily satisfied with available services since they are less likely to have serious coexistent burdens of ill health as it is common among older individuals (24).

This study has shown that civil servants were found to be less satisfied with care compared with those who were in the private sector. In an earlier study conducted among pregnant women in Ethiopia, it was reported that compared with their counterparts, women who attained tertiary education and those whose income was high were less likely to be satisfied with care (7). In developing countries, and compared with individuals who did not acquire western education, formal sector workers (civil servants) are generally better educated and with fairly good and consistent income (25). Another possible explanation is that information on the quality of care as could be available to informal sector enrollees and better-educated people who were less satisfied with care could be on the quality of care available in better health systems in other countries. Quality of care is usually better in other climes that are perceived to be better than what obtains in the health system in Nigeria, thus their nonsatisfactory experience with care under the NHIS. Education and higher socioeconomic status are factors that could enhance access to more information about available best health care practices in many other settings. Thus, those who have access to information on better health care services may be less easily satisfied with available health care services especially when such are not as good as the ones available elsewhere.

The expectation of the high quality of service as could be found among the highly educated formal sector employees, but receiving a lower quality of care than expected is a factor of dissatisfaction among them. A recent study among dental patients in a South Indian Research Centre is suggestive of a lower level of satisfaction with healthcare service among highly educated individuals (26). This contrasts 
with the much lower expectation among the less educated or those with inconsistent income whose expectation is usually not as high, among whom the tendency to be easily satisfied with available care is much higher. This is much more so as it is common among the poor in developing countries characterized by health care resource constraints and who are usually less informed about the quality of health services in other climes (27). It has been postulated that individuals with low base-level expectations of quality of health care service are easily satisfied with available services than are those whose expectations are above the base level. These expectations are referred to as exchange and communal trust norms respectively (23). In this study, because of what consistent income and a higher level of education may have afforded them, civil servants may have exhibited communal trust norms and were thus less satisfied with available care. This is unlike those in the private sector whose satisfactory disposition to health care may have been an exhibition of exchange trust norm. Thus, the private sector tends to be more satisfied with available care especially, as it was in this present study when the choice of health facility was an outcome of active search for facilities that were considered to have the capability to render quality care. The phenomenon of exchange trust norm may explain the satisfaction among those who had no knowledge of the NHIS, the scheme's responsibilities toward enrollees and thus expected less from it with an ultimate feeling of satisfaction with basic services rendered to them in the accredited facilities.

In this study, those who did not seek information about the quality of care before choosing a facility were less satisfied with care. Studies have shown that generally, individuals do not seek quality health facilities, but they mainly rely on others to assist them to do that. The choice not to actively seek a quality of care may solely be based on the fact that they do not take such as important or have limited capacity to do so (9). The freedom to choose a preferable health facility sometimes is restricted because of the influence of a third party such as an insurer and other stakeholders in the health insurance industry $(2,9)$. However, currently, the influence of insurers on the choice of health care facilities under the NHIS is not too clear. Thus, the effect of a possible influence on satisfaction with service is not certain yet. On the other hand, some who made the effort to seek information about the quality of care of facilities before enrollment may have come to terms with the quality of services obtained in such facilities and thus expressed satisfaction with what was made available to them.

Diverse opinions exist about satisfaction with care in public and private health facilities. Preference for a type of health care facility is suggestive of a perceived efficiency, responsiveness, and therefore experience of high satisfaction with care (9). In a systematic review conducted in selected facilities across many European countries, while findings from many of the countries showed higher satisfaction with care in public facilities, findings from some of the countries reported higher satisfaction with care in private health facilities (8). Yet, in another systematic review of some thousands of hospitals conducted across nine European countries, generally, public health care facilities were rated higher in quality of service and satisfaction with care among service recipients than it was reported in private-not for-profit and private for-profit facilities in that order (28). This was in line with findings of higher levels of satisfaction with care by another study conducted in Kenya among mothers of newly born in selected public and private hospitals (29). However, in yet another systematic study conducted in selected public and private health facilities in some low and middle-income countries, findings showed a higher experience of satisfaction with care was reported in private facilities than were in public facilities (30). This was in agreement with a similar study in Southwest Nigeria (31) and as well as in a systematic review conducted in India among parents of children admitted in some selected hospitals which also reported satisfaction with services provided by private health services arrangement (32).

This study is in support of experience of higher satisfaction with care among those who patronized private faithbased facilities. An experience of a higher level of satisfaction with health services in faith-based facilities is suggestive of better quality service than was rendered in public facilities.

\section{Limitation}

This study acknowledges that there may have been an over-or underrepresentation of particular patterns and a greater risk of data manipulation associated with systematic sampling methods. In addition, the findings of a study with a larger population size would have been more representative of the study findings because a smaller study population can bias the population as non-study participants will be different than those who get to be part of the process. These limitations are well acknowledged.

\section{Conclusion}

Findings in this study conclude that the quality of care in the NHIS accredited facilities was generally low, and may have contributed to the low level of population coverage of the scheme. This study has shown that situations that are suggestive of health literacy such as seeking quality healthcare services and a likely absence of barriers to do so are likely to improve satisfaction with healthcare. Stakeholders in the NHIS should implement policies that will enhance the health literacy of potential beneficiaries of the scheme. It is believed that this will improve satisfaction with care among enrollees, facilitate uptake of and continuity with available care. Ultimately, it would assist in the attainment of universal health coverage, and improved population health for growth and development.

\section{Declaration of Conflicting Interests}

The author(s) declared no potential conflicts of interest with respect to the research, authorship, and/or publication of this article. 


\section{Ethical Approval}

Ethical approval to conduct the study was sought and obtained at the Oyo State Ethical Review Committee, Ref. No. AD 13/479/596. Likewise, the research was approved by the Ethics Committee of the University of Cape Town, South Africa, HREC REF 536/ 2018. The design of the work conforms to standards currently applied in Nigeria. Study participants' consent was sought and obtained.

\section{Funding}

The author(s) received no financial support for the research, authorship and/or publication of this article.

\section{ORCID iD}

David Ayobami Adewole (iD https://orcid.org/0000-0002-4660-4198

\section{Statement of Human and Animal Rights}

The study interviews were conducted in accordance with the Oyo State Nigeria Ethical Review Committee and the Ethics Committee of the University of Cape Town, South Africa.

\section{Statement of Informed Consent}

Written and verbal informed consent were obtained from the study respondents for their anonymized information to be published in this article.

\section{References}

1. Mohammed S, Bermejo JL, Souares A, Sauerborn R, Dong H. Assessing responsiveness of health care services within a health insurance scheme in Nigeria: users' perspectives. BMC Health Serv Res. 2013;13(1):1.

2. Bes RE, Wendel S, Curfs EC, Groenewegen PP, de Jong JD. Acceptance of selective contracting: the role of trust in the health insurer. BMC Health Serv Res. 2013;13:375.

3. Kleefstra SM, Kool RB, Veldkamp CM, der Meer AC W-v, Mens MA, Blijham GH, et al. A core questionnaire for the assessment of patient satisfaction in academic hospitals in The Netherlands: development and first results in a nationwide study. Qual Saf Health Care. 2010;19(5):e24.

4. Woldeyohanes TR, Woldehaimanot TE, Kerie MW, Mengistie MA, Yesuf EA. Perceived patient satisfaction with in-patient services at jimma university specialized hospital, southwest Ethiopia. BMC Res Notes. 2015;8:285.

5. Sanders SR, Erickson LD, Call VR, McKnight ML, Hedges DW. Rural health care bypass behavior: how community and spatial characteristics affect primary health care selection. J Rural Health. 2015;31(2):146-56.

6. Abolfotouh MA, Al-Assiri MH, Alshahrani RT, Almutairi ZM, Hijazi RA, Alaskar AS. Predictors of patient satisfaction in an emergency care centre in central Saudi Arabia: a prospective study. Emerg Med J. 2017;34(1):27-33.

7. Chemir F, Alemseged F, Workneh D. Satisfaction with focused antenatal care service and associated factors among pregnant women attending focused antenatal care at health centers in jimma town, jimma zone, south west Ethiopia; a facility based cross-sectional study triangulated with qualitative study. BMC Res Notes. 2014;7:164. -.

8. Kruse FM, Stadhouders NW, Adang EM, Groenewoud S, Jeurissen PPT. Do private hospitals outperform public hospitals regarding efficiency, accessibility, and quality of care in the european union? A literature review. Int $\mathrm{J}$ Health Plann Manage. 2018;33(2):e434-e53.

9. Victoor A, Delnoij DM, Friele RD, Rademakers JJ. Determinants of patient choice of healthcare providers: a scoping review. BMC Health Serv Res. 2012;12(1):1.

10. Geberu DM, Biks GA, Gebremedhin T, Mekonnen TH. Factors of patient satisfaction in adult outpatient departments of private wing and regular services in public hospitals of Addis Ababa, Ethiopia: a comparative cross-sectional study. BMC Health Serv Res. 2019;19(1):869. doi: 10.1186/s12913-019-4685-x. PMID: 31752821; PMCID: PMC6873435.

11. Fufa BD, Negao EB. Satisfaction of outpatient service consumers and associated factors towards the health service given at jimma medical center, south west Ethiopia. Patient Relat Outcome Meas. 2019;10:347-54.

12. Federal Ministry of Health Nigeria. Strategic Review of Nigeria's National Health Insurance Scheme. Abuja Nigeria; 2014.

13. Arin D, Hongoro C. Scaling up national health insurance in Nigeria: learning from case studies of India, Colombia, and Thailand. Washington, DC: futures group. Health Policy Project. 2013. https://www.healthpolicyproject.com/index.cfm? $\mathrm{id}=$ publications \& get $=$ publD\&publD $=96$

14. Atun R, de Andrade LO, Almeida G, Cotlear D, Dmytraczenko T, Frenz P, et al. Health-system reform and universal health coverage in latin america. Lancet (London. England. 2015;385(9974):1230-47.

15. Saksena P, Antunes AF, Xu K, Musango L, Carrin G. Mutual health insurance in Rwanda: evidence on access to care and financial risk protection. Health policy (Amsterdam. Netherlands. 2011;99(3):203-9.

16. National Population Commission. Nigeria (2006): Census. Accessed March, 2021. http://www.population.gov.ng/index.php/censuses.

17. Kish L. Survey sampling. 1965.

18. United States Agency for International Development. The Demographic and Health Surveys Rockville, MD 20850 USA; 2017. Accessed April, 2021. https://dhsprogram.com/ What-We-Do/Survey-Types/SPA.cfm.

19. Ambelie YA, Demssie AF, Gebregziabher MG. Patients' satisfaction and associated factors among private wing patients at bahirdar felege hiwot referral hospital. North West Ethiopia. Sci J Public Health. 2014;2(5):417-23.

20. Rajbanshi L, Dungana G, Gurung Y, Koirala D. Satisfaction with health care services of out patient department at chitwan medical college teaching hospital. Nepal. Journal of Chitwan Medical College. 2014;4(1):11-8.

21. Footman K, Roberts B, Mills A, Richardson E, McKee M. Public satisfaction as a measure of health system performance: a study of nine countries in the former soviet union. Health policy (Amsterdam, Netherlands). 2013;112(1-2):62-9. 
22. Mezemir R, Getachew D, Gebreslassie M. Patients' satisfaction and its determinants in outpatient department of deberebirhan referral hospital, north shoa. Ethiopia. Int J Econ Manag Sci. 2014;3(191):2.

23. Ward PR, Rokkas P, Cenko C, Pulvirenti M, Dean N, Carney AS, et al. 'Waiting for' and 'waiting in' public and private hospitals: a qualitative study of patient trust in south Australia. BMC Health Serv Res. 2017;17(1):333.

24. Oni T, McGrath N, BeLue R, Roderick P, Colagiuri S, May $\mathrm{CR}$, et al. Chronic diseases and multi-morbidity-a conceptual modification to the WHO ICCC model for countries in health transition. BMC Public Health. 2014;14(1):1.

25. Kimani JK, Ettarh R, Kyobutungi C, Mberu B, Muindi K. Determinants for participation in a public health insurance program among residents of urban slums in Nairobi, Kenya: results from a cross-sectional survey. BMC Health Serv Res. 2012;12:66. Published online 2012. doi: 10.1186/ 1472-6963-12-66 PMCID: PMC3317843.

26. Seenivasan M, Banu F, Inbarajan A, Natarajan P, Natarajan S. Anand Kumar V., et al. The consequence of complete dentures on quality of life of edentulous patients in the south-Indian population based on educational and socioeconomic grades. Cureus. 2020;12(2):e6923.

27. Chuma J, Mulupi S, McIntyre D. Providing financial protection and funding health service benefits for the informal sector: Evidence from sub-Saharan Africa. RESYST Working Paper
2. Cape Town South Africa; 2017. Accessed April 18, 2021. http://resyst.1shtm.ac.uk/sites/resyst.lshtm.ac.uk/files/docs/ reseources/WP2_financialprotection.pdf. uk/files/docs/ reseources/WP2_financialpro tection. pdf, dernière visite le 4 septembre; 2013.

28. Tynkkynen L-K, Vrangbæk K. Comparing public and private providers: a scoping review of hospital services in Europe. BMC Health Serv Res. 2018;18(1):141.

29. Okumu C, Oyugi B. Clients' satisfaction with quality of childbirth services: a comparative study between public and private facilities in limuru Sub-county, kiambu, Kenya. PloS one. 2018;13(3):e0193593-e.

30. Berendes S, Heywood P, Oliver S, Garner P. Quality of private and public ambulatory health care in low and middle income countries: systematic review of comparative studies. PLoS Med. 2011;8(4):e1000433-e.

31. Oredola AS, Odusanya OO. A survey of the perception of the quality of and preference of healthcare services amongst residents of abeokuta south local government, ogun state, Nigeria. Niger J Clin Pract. 2017;20(9):1088-97.

32. Baliga BS, Ravikiran SR, Rao SS, Coutinho A, Jain A. Public-Private partnership in health care: a comparative crosssectional study of perceived quality of care Among parents of children admitted in Two government district-hospitals, southern India. J Clin Diagn Res. 2016;10(2):Sc05-9. 